
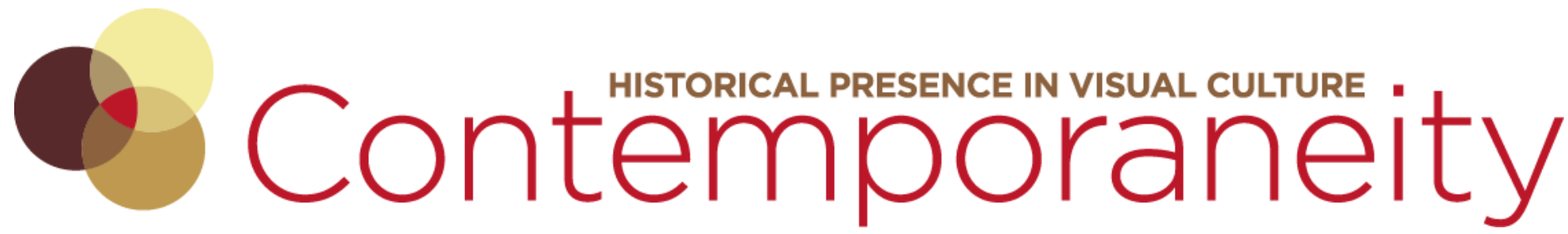

Vol 5, No 1 "Agency in Motion" (2016) | ISSN 2155-1162 (online) | DOI

\title{
SuperQueeroes - Our LGBTI* Comic Book Heroes and Heroines Schwules Museum*, January 22-June 26, 2016
}

Carlos Kong

\section{Exhibition Review}

SuperQueeroes - Our LGBTI* Comic Book Heroes and Heroines at the Schwules Museum*, Berlin, January 22-June 26, 2016.

\section{About the Author}

Carlos Kong is a postgraduate student at The Courtauld Institute of Art, London. He researches questions of sexuality, historical memory, and intercultural encounter across contemporary art, literature, and media. He received his BA from Cornell University, and was previously the Baden-Württemberg Foundation Fellow at Universität Heidelberg, Germany. 


\section{SuperQueeroes - Our LGBTI* Comic Book Heroes and Heroines}

\author{
Schwules Museum*, \\ January 22-June 26, 2016
}

Carlos Kong

SuperQueeroes - Our LGBTI* Comic Book Heroes and Heroines at the Schwules Museum* in Berlin (January 22, 2016-June 26, 2016) presents the first major exhibition of queer comics in Europe. ${ }^{1}$ Comprised of works by nearly one hundred comics artists and organized by seven curators, SuperQueeroes provides a comprehensive survey of comics with LGBTI characters and narratives, primarily from Europe and the United States. ${ }^{2}$ The exhibition illustrates the inventiveness and plurality of nonnormative sexual cultures to which comics graphically testify (fig. 1). As a foundational endeavor, SuperQueeroes raises a two-fold fundamental challenge-narrating sexual diversity through the disparate histories of its literary and visual representation; and curating comics in attune ment to their historical and material specificity. A critical examination of SuperQueeroes's moments of insight and inconsistency is relevant for the future scholarly and artistic work on queer comics that the exhibition will likely inspire.

Once relegated to the realms of the low and the vernacular within the mass cultural industry, comics have recently and continue to emerge within academic, curatorial, and archival contexts, redefining the scope and methodologies of cultural inquiry. Through their serial interrelation of images and texts, the manual and the mechanically reproduced, and the autobiographical and the fantastical, comics remain an elusive medium in spite of their quotidian ubiquity. While comics share affinities of genre with pop art, DIY practices, illuminated manuscripts, serial literature, and filmstrips, they remain graphically unique in literary and visual stylization.

In both their industrial norms and depicted content, comics have conventionally reflected and imagined hegemonically heteronormative worlds, particularly through the figure of "the superhero" and its implicit heroization of heterosexuality, male dominance, physical strength, and idealized bodies (Superman remains a prime example). However, recent comics and their scholarly reception have attenuated this dominant convention, in turn producing and describing the relation between comics and minoritarian historical representation. As literary and comics scholar Hillary Chute contends, "[c]omics-as a form that relies on space to represent time-becomes structurally equipped to challenge dominant modes of storytelling and history writing. ${ }^{\prime 3}$ The contestation of dominant historical narration

\footnotetext{
1 SuperQueeroes defines "queer comics" as "comics that include LGBTI characters and tell LGBTI stories." This definition elides "queer" and "LGBTI" and us es "queer" as an umbrella signifier for "LGBTI." This prefigures my forthcoming comments on the terminological and historical tension between specifically gay politics and queer as a politics, evident in the exhibition's section on mainstream comics. For the purposes of my review, I will continue to use the term "queer comics." See http://www.s chwules mus eum.de/en/exhibitions/view/s uperqueeroes-our-lgbti-comic-book-heroes-andheroines/

${ }^{2}$ While the geographic scope of SuperQueeroes is Europe and the U nited States, the exhibition includes a section on the important work of Gengoroh Tagame, a leading Japanese artist whose work features gay characters and homoerotic, and often violent, graphic narratives in the manga comics tradition.

${ }^{3}$ Hillary Chute, "Comics as Literature? Reading Graphic Narrative," PMLA 123, no. 2 (March 2008): 456.
} 
within the discursive and representational space of comics is most compellingly rehearsed in the exhibition's transposition of superheroes into the eponymous SuperQueeroes, positing the figures in comics as sites of heroic queer reimagining and the medium of comics as its privileged form.

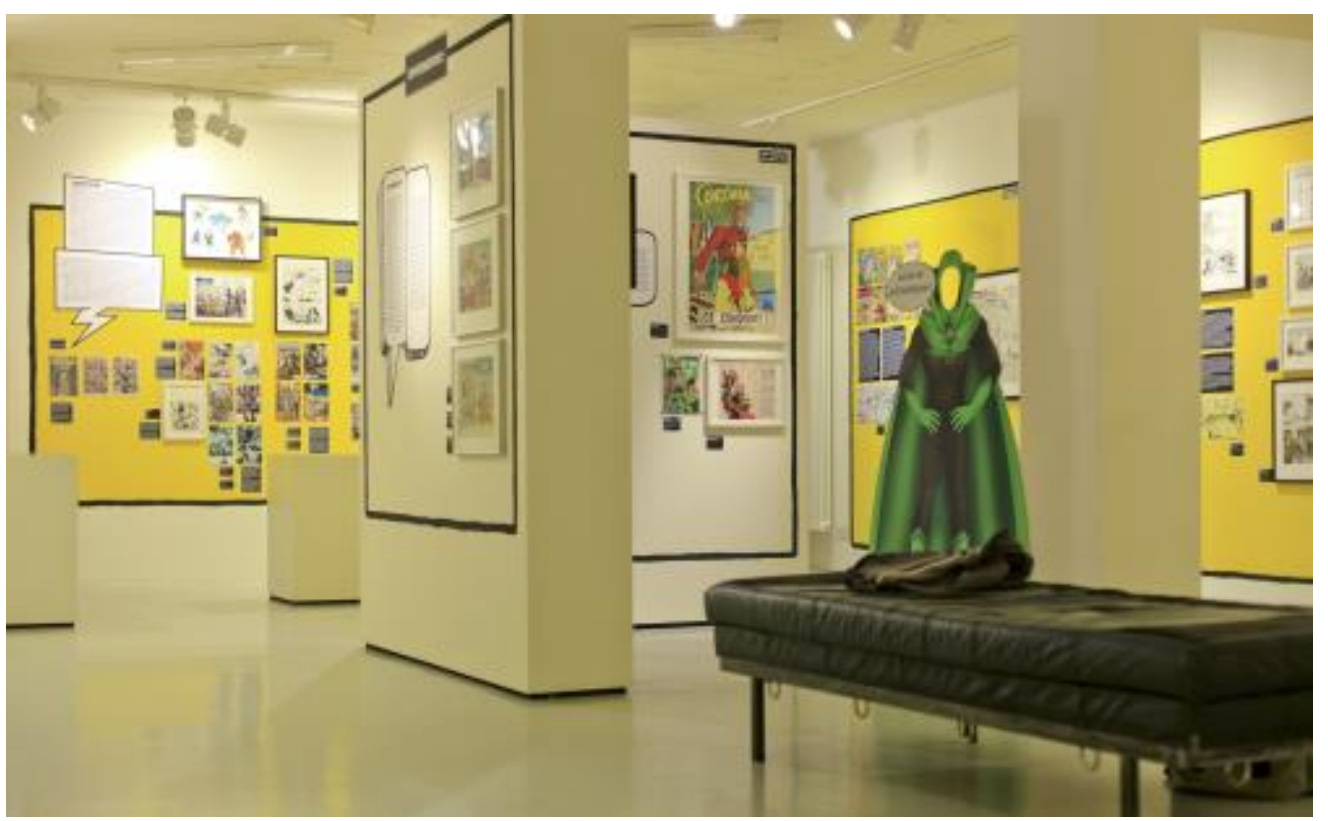

\section{Figure 1}

Installation view, entrance (from right), SuperQueeroes - Our LGBTI* Comic Book Heroes and Heroines, Schwules Museum*, Berlin, curated by Michael Bregel, Kevin Clarke, Natasha Gross, Hannes Hacke, Justin Hall, Markus Pfalzgraf, Mario Russo. P hotograph courtesy Robert M Berlin/Schwules* Museum.

In opening wall texts, the curators set the historical parameters of SuperQueeroes as the late 1960 s through the present, encapsulating a period beginning with the Stonewall Riots of 1969 through the consequent and varied formations of sexual politics in recent history. As the apotheosis of the gay liberation struggles of the 1960s, Stonewall symbolically ushered in a new era marked by the personalization of politics, specifically the public urgencies of gay and lesbian visibility, gender and sexual self-identification, and communal solidarity. Despite the American (US) focus of this narrative, the historical framework of the late 1960 s through the present productively structures SuperQueeroes without feeling reductive or prescriptive, since the exhibition is grouped around various themes-independent queer comics from the United States, independent queer comics from Europe, mainstream comics, everyday heroes, the comics author as hero, queer approaches to comics genres (cowboys, cops, adventurers), comics and AIDS, and the censorship of comics. ${ }^{4}$

\footnotetext{
${ }^{4}$ SuperQueeroes also includes a small section on Tom of Finland (Touko Laaksonen), whose pre- and post-Stonewall homoerotic drawings influenced the exhibition's post-Stonewall comics artists. For an important study on gay graphic arts before Stonewall, see Thomas Waugh, Out/Lines: Underground Gay Graphics From Before Stonewall (V ancouver: A rsenal Pulp Press, 2002).
} 
The post-Stonewall time frame is signified by the exhibition's displays of the proliferating queer comics culture in the United States, wherein the work of many nowrenowned independent practitioners beginning their careers in the 1970-80s-like Mary Wings, Alison Bechdel, Jennifer Camper, and Roberta Gregory-was streamlined and published under Howard Cruse's Gay Comix series (1980-1998). In contrast to this linear development in American queer comics history, the European comics presented provide an instructive counterpoint to the exhibition's chronology. Created under varying cultural and geopolitical circumstances, the work of the European artists featured, such as Ralf König (Germany), Nazario (Spain), Luca Enoch (Italy), Helena Janecic (Croatia), and Beata "Beatrix" Cymerman (Poland), evinces a multitude of queer experience against a singular historical narrative. Their works emerged autonomously and precariously in locally specific contexts, often with neither formal networks of queer exchange nor social landscapes of queer acceptance.

Both American and European independent queer comics challenge dominant histories by bearing witness to an astonishing plurality of queer experience - the curators' most captivating statement. From the quotidian to the spectacular, the asexual to the pornographic, the disabled to the fat to the dressed in drag, the exhibition testifies a politics rooted in a heterogeneity of sexual intersections and erotic encounters that queer comics artists actively reimagine in graphic narrative form. Rupert Kinnard's B.B. and the Diva (1979) depicts the first gay and lesbian-identified African-American protagonists in comics, while Justin Hall's Glamazonia (2010) portrays the adventures of the eponymous "Uncanny Super-Tranny." Gaye Mae Kincaid's Sapphowoman and the Greater Belfast Dykes (1980) references literary history by reinventing Sappho, the Ancient Greek homoerotic poet, as a lesbian superhero of Northern Ireland. A central section on the AIDS crisis further articulates the didacticism of independent comics as instruments of safe sex education and stigma fighting. ${ }^{5}$ These depictions of sexual plurality within the representational and social spaces of independent comics materialize many political worlds of queer life, pleasure, and activism, which SuperQueeroes convincingly advocates against cultural norms of invisibility and erasure.

A section on mainstream comics proves to be less successful (fig. 2). The introductory wall text argues that social progress is evincible through the increased visibility of nonnormative sexualities in mainstream comics. Various depictions of LGBTI characters and narratives in mainstream comics are presented, yet the central display of the $\mathrm{X}$-Men comic books featuring the superhero Northstar exemplifies the section's broader oversights. In 1992, Marvel expanded the scope of sexual representation in mainstream comics when writers determined that Northstar would come out as gay. Twenty years later following the legalization of same-sex marriage in New York, Marvel depicted "the first gay wedding" in comics when Northstar married his long-term partner Kyle. ${ }^{6}$ SuperQueeroes celebrates Northstar's narrative as a prime example of cultural acceptance and social change on behalf of Marvel comics and its audience.

\footnotetext{
${ }^{5}$ For more information on sex educationalcomics and censorship during the A I DS crisis, see Douglas Crimp, "How to Have Promiscuity in an Epidemic," in "A IDS: Cultural Analysis/Cultural A ctivism," ed. Douglas Crimp, special issue, October 43 (Winter 1987): 237-271.

${ }^{6}$ For details see Matthew Perpetua, "Marvel Comics Hosts First Gay Wedding in 'Astonishing X - Men'," Rolling Stone, May 22,2012, http://www.rollingstone.com/culture/news/marvel-comics-hosts-first-gaywedding-in-astonishing-x-men-20120522.
} 


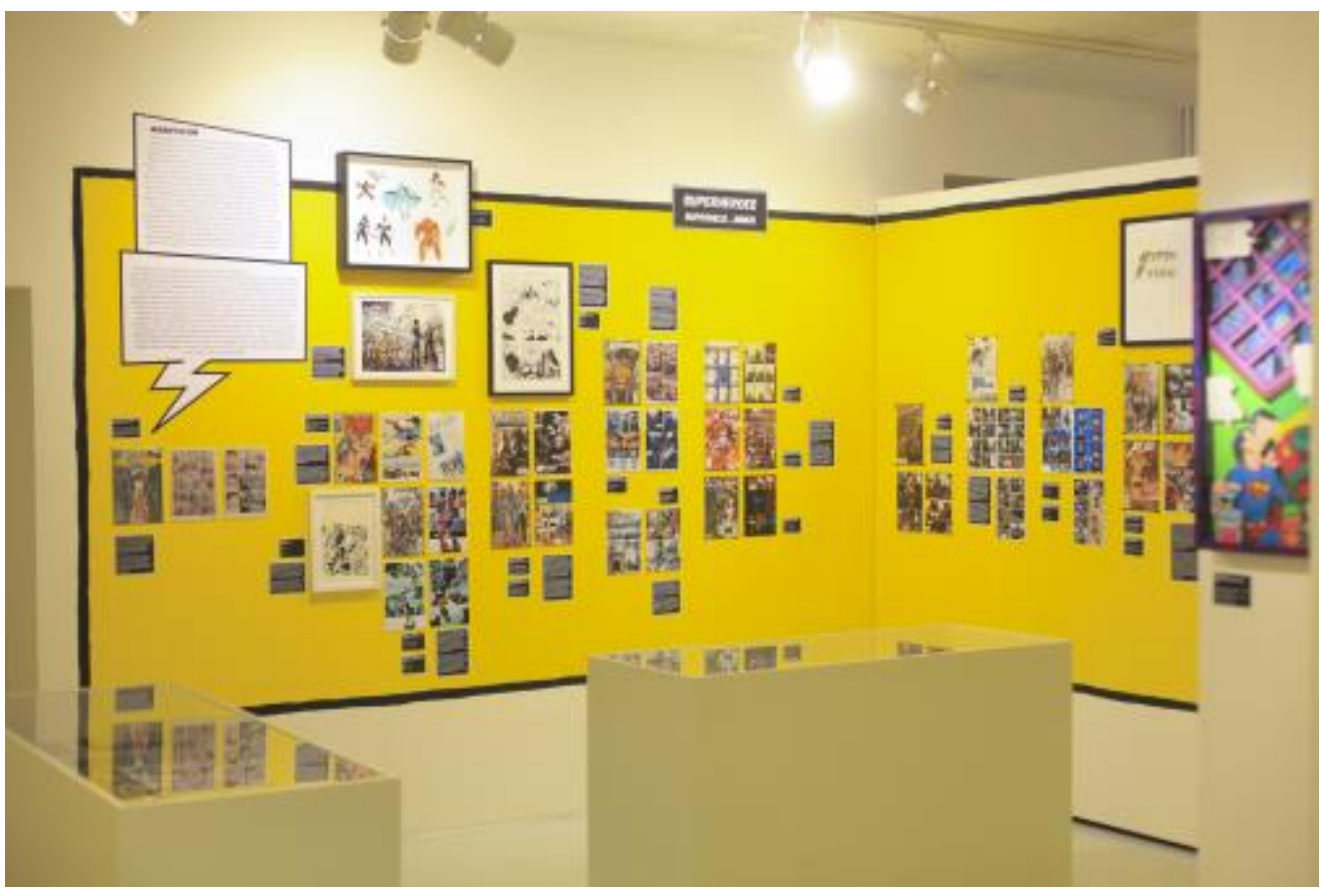

\section{Figure 2}

Installation view, "Mainstream" section, SuperQueeroes - Our LGBTI* Comic Book Heroes and Heroines, Schwules Museum*, Berlin, curated by Michael Bregel, Kevin Clarke, Natasha Gross, Hannes Hacke, Justin Hall, Markus Pfalzgraf, Mario Russo. P hotograph courtesy Robert M Berlin/Schwules* Museum.

Northstar's story, among others, reflects the departure of mainstream comics from their heteronormative industrial moorings, as well as productively expands the sphere of representations rendered legitimate, both within and beyond comics. Nevertheless, one must question whether narratives like Northstar's simply react to a dominant teleology of mainstream gay politics, rather than actively envisioning a politics rooted in the heterogeneity of queer experience. ${ }^{7}$ While the independent comics presented testify a diversity of desires through affective and imaginative representations derived from lived realities, the mainstream comics section compounds the pragmatic reduction of queer politics into gay visibility. ${ }^{8}$ This instance counterproductively risks advocating a "homonormative time line," where linear gay expectations either hegemonically singularize queer lives or further pathologize ones that fail to conform. ${ }^{9}$ Moreover, the challenges raised by the

\footnotetext{
${ }^{7}$ The exhibition does not consider the economic dimension of comic books as commodities, though the inclusion of LGBTI characters in mains tream comics nonetheless suggests the opening of the comics industry to new consumer demographics.

${ }^{8}$ For a compelling critique of the "gay pragmatis m" of the marriage agenda as well as an articulation of a utopian hermeneutics of queer representation, see José Esteban Muñoz, Cruising Utopia: The Then and There of Queer Futurity (New York: NYU Press, 2009), $19-32$.

9 See Nguyen Tan Hoang's response in Carolyn Dinshaw et al, "Theorizing Queer Temporalities: A Roundtable Discussion," GLQ: A Journal of Gay and Lesbian Studies 13, no. 2-3 (2007): 182-185.
} 
normatively "progressive" narratives of mainstream comics reflect the exhibition's broader elision of "queer comics" with "LGBTI stories," whereby queer is conflated with the individual (and unequally distributed) politics of sexuality and gender assumed under "LGBTI." Thus in contradistinction to a mainstream gay politics of acceptance and assimilation, which too often stands in for "LGBTI," "queer" antagonistically emerged as a sexual politics of world-building against normativity - both projects being necessary, historically contingent, and irreducible. Nonetheless what SuperQueeroes makes clear, and fails to question, is that mainstream comics follow from mainstream gay politics.

Beyond the productive questions of sexual representation that surface throughout SuperQueeroes, one technical limitation of the exhibition lies in the challenges of curating in accordance to the multifaceted medium-specificities of comics. Affixed to the gallery walls painted with black frames and yellow backgrounds to imitate a comic strip's graphic structure, most comic books were represented solely by their covers or were opened to a singular narrative moment, reducing longer stories to their most striking images (fig. 2). While comics are at once verbal and visual, they are fundamentally a tactile medium to be flipped through and read closely. Moreover, the affective and identificatory power of comics lie in their narrative temporality as well as in the intimate and embodied relation of comic book to the reader. By excluding the possibility of holding and reading the comics on display, SuperQueeroes unintentionally undermined both the narrative and tactile dimension of comics as a book form. Instead, the exhibition privileged optical experience, images over text, and a selective narrative interpretation, and further necessitated a strong reliance on explanatory wall texts for curatorial cohesion. This could have been easily rectified with a small sample of comics available to be actually read, underscoring their circulatory potential as a mechanically reproduced medium designed for reading, sharing, and the building of community and solidarity.

The final section on censorship deftly frames the rhetoric of heroization that runs throughout SuperQueeroes. On display is Frederic Wertham's 1954 study Seduction of the Innocent, where the German-American psychiatrist maintained that comics lead to juvenile delinquency and homosexuality. From his earlier writings through Seduction of the Innocent, Wertham's work both reflected and contributed to the postwar milieu of public paranoia and fear of external contamination. Its exposition and critique of the supposed negative effects of reading comics proffered a stricter revision of the Comics Code-the industry's standards implemented by comic book publishers-in addition to further establishing a norm of selfcensorship among comics artists. ${ }^{10}$ Through an archival mapping of documentary photographs and newspaper articles, SuperQueeroes visualizes the widespread institutionally organized burnings of comics throughout the United States and Europe following Wertham's publication and the tightening of the Comics Code. The censorship, sexual pathologization, and mass burning of comics that SuperQueeroes presents, as well as the exhibition's contextual interpolation into the cultural fabric of Berlin, draw an implicit and unsettling twofold parallel to specters of German history - the persecution of homosexuals in Nazi Germany and the nation-wide book burnings of 1933. While implicating an open and reflective relation to national history, SuperQueeroes reorients and compounds the courage of recreating queer life in comics - the medium that, as Hillary Chute argues, makes "visible the site of one's inscriptional effacement." 11 Against the inscriptional effacements of censorship, persecution

\footnotetext{
${ }^{10}$ For a detailed history of the Comics Book Code, see Amy Kiste Nyberg, Seal of Approval: The History of the Comics Code (Jackson: University of Mississippi Press, 1998).

${ }^{11}$ Hillary Chute, "The Texture of Retracing in Marjane Satrapi's 'Persepolis'," Women's Studies Quarterly 36, no. $1 / 2$ (Spring-Summer 2008): 106.
} 
histories, and heteronormative cultural narratives, SuperQueeroes illustrates the exhilarating plurality of queer comics and the durability of the lives that they heroically testify.

$(\mathrm{cc}) \overline{\mathrm{EY}}$ New articles in this journal are licensed under a Creative Commons Attribution 4.0 United States License.

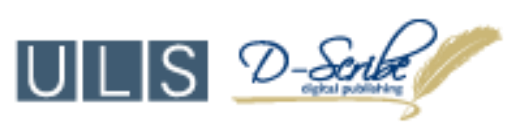

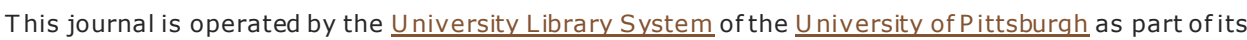
D-Scribe Digital Publishing Program, and is co-sponsored by the University of Pittsburgh Press. 